\title{
Actualidad institucional y económica de España en el marco de la Unión Europea (Junio 2020)
}

\author{
Beatriz Iñarritu \\ Profesora de la 'Deusto Business School' \\ Universidad de Deusto
}

doi: http://dx.doi.org/10.18543/ced-63-2020pp359-379

Sumario: I. Introducción.-II. El Estado de la Integración.-III. Cuestiones generales de la actualidad económica

\section{Introducción}

El primer semestre de 2020 será recordado en la historia económica y política de la UE por la crisis sanitaria derivada de la pandemia del coronavirus.

Europa, y el mundo entero, se paralizaron, y la UE debió adoptar decisiones de urgencia para apoyar a los Estados miembros más afectados, como Italia y España. Al programa de emergencia y a la decidida acción del BCE se sumó el debate sobre un plan de recuperación, que se antoja difícil ya que contempla la posibilidad de realizar transferencias a fondo perdido, y un plan para proteger a las empresas europeas respecto a la entrada en su capital de empresas extranjeras que se hubieran beneficiado de ayudas públicas.

Asimismo, se produjo la salida «política» del Reino Unido de la UE el 31 de Enero, a la espera del cierre de las negociaciones comerciales y económicas sobre la futura relación entre ambas partes. Y en Febrero dio comienzo un debate clave sobre la eventual reforma de ciertos instrumentos de la «Gobernanza Económica» de la Unión.

The first six months of 2020 will be remembered in the EU economic and political history for the sanitary crisis derived from the coronavirus pandemic.

Europe, and the whole world, paralyzed, and the EU had to adopt urgent decisions to support those most affected member States, like Italy and Spain. The emergency program and the ECB determined action were accompanied by the debate about a recovery plan, which sounds to be 
difficult as it foresees the possibility of implementing economic transfers (grants), and a plan to protect European companies from the entry in their capital of foreign enterprises that might take advantage of public aids.

The 'political' withdrawal of the United Kingdom from the EU took place on 31 January, although waiting for the closure of the trade and economic negotiations on the future relationship between both parts. And a key debate on the eventual reform of certain instruments of the 'Economic Governance' of the EU started in February.

\section{El estado de la integración}

\section{El Programa de emergencia de apoyo a las Economías europeas más} afectadas por la pandemia del coronavirus: 540.000 millones de euros

Los ministros de Economía y Finanzas de la Eurozona alcanzaron el 9 de Abril un acuerdo sobre un paquete de medidas que habilitaba más de 500.000 millones de euros en préstamos dirigidos a los Estados miembros más afectados por la pandemia del coronavirus.

Así, el Mecanismo Europeo de Estabilidad, MEDE, debería proporcionar hasta 240.000 millones de euros en líneas de crédito a los Estados más afectados por el virus, el Banco Europeo de Inversiones, BEI, movilizaría 200.000 millones en préstamos para empresas y, por último, un nuevo fondo creado para combatir los efectos de la crisis en el empleo, propuesto por la Comisión Europea y conocido como SURE, debería poner a disposición de los gobiernos europeos otros 100.000 millones.

El acuerdo fue refrendado posteriormente en el Consejo Europeo celebrado el 23 de Abril y puso en marcha, por tanto, una «triple» red de seguridad para el «rescate» de las Economías más afectadas por la pandemia alcanzando una cifra global de 540.000 millones de euros.

Por lo que se refiere al primer instrumento, en una reunión posterior, que tuvo lugar a comienzos de Mayo, el mismo Eurogrupo pactó que el crédito de hasta 240.000 millones de euros del MEDE tendrá un plazo de 10 años y que se ofrecerá con un tipos de interés del $0,115 \%$ y que, a diferencia de otras operaciones instrumentadas a través de este fondo de rescate, su adjudicación no deberá implicar condicionalidad, por lo que los países no deberán afrontar el control de la «troika» compuesta por los representantes de la Comisión Europea, el Banco Central y el Fondo Monetario Internacional.

De esta forma, el MEDE pondrá a disposición de todos los países de la zona euro una cantidad equivalente al $2 \%$ de su PIB para hacer frente a los costes sanitarios de la pandemia, sin condiciones vinculadas al uso de 
esa ayuda. Los países no tendrán que firmar un Memorándum de entendimiento, como en anteriores rescates, sino que únicamente deberán presentar un «plan de respuesta a la pandemia» que incluya todos los gastos que necesitarán financiar.

Es así que el comisario de Economía, Paolo Gentiloni, insistió, tras la consecución del pacto, en el hecho de que sería el ejecutivo comunitario quien se responsabilizará de controlar el uso de los fondos para que, en efecto, se destinen a combatir la covid-19.

El director del MEDE, Klaus Regling, recordó que gracias a la calificación crediticia de triple A del Mecanismo, los países «podrán obtener un crédito a unos tipos muy favorables».

Respecto a este «rescate sin condiciones», ya en marzo los ministros de Finanzas de los Veintisiete, en su composición de Consejo de la UE conocido como Ecofin, habían dado luz verde a que los países de la Unión Europea más afectados por el brote de la Covid-19 pudieran acogerse a la «flexibilidad» que contempla el Pacto de Estabilidad y Crecimiento respecto al compromiso de los Estados en materia de disciplina fiscal.

El presidente del Eurogrupo, Mário Centeno, recordó que el gasto público extraordinario «deberá ser temporal y estar vinculado a la crisis sanitaria».

Pese a que el portugués encabezaba entonces el Eurogrupo, el organismo que reúne a los 19 ministros de Finanzas de la zona euro, la invitación a la cita se extendió a los otros ocho titulares de Economía y Finanzas de la UE de los países que no forman parte de la Unión Monetaria. En la reunión se abordaron los primeros efectos de la epidemia sobre la actividad económica y en su comunicado final los ministros dieron el visto bueno a la posibilidad de que la Comisión Europea flexibilizara el cumplimiento de las reglas fiscales. La principal beneficiada sería Italia, ya que este país se enfrentaba al doble desafío de hacer frente a la emergencia sanitaria y de contener una Deuda pública que lleva años superando el 135\% del PIB.

Por su parte, el rescate que proporcionaría el BEI se realizará a través de un fondo de garantía de 25.000 millones de euros que permitirá inyectar 200.000 millones en el tejido empresarial europeo a través de líneas de crédito.

Y el tercer componente del rescate, el SURE, deberá apoyar a los países en sus programas dedicados a sostener las rentas de los trabajadores afectados por la pandemia. Se prevé una línea de préstamos de hasta 100.000 millones de euros que podrán solicitar países como España para sufragar las medidas de apoyo a autónomos o de financiación del elevado coste de los ERTE.

Este fondo temporal se articulará mediante la emisión de Deuda por parte de la Comisión, contando con el aval del presupuesto de la UE en un $75 \%$ y de los propios Estados miembros en un $25 \%$. 
Asimismo, y con el mismo objetivo de apoyar la emergencia económica, también en Abril la Comisión Europea envió a los Estados miembros una propuesta para ampliar el alcance del marco temporal de las ayudas estatales adoptado por la UE para permitir a los Estados miembros llevar a cabo las recapitalizaciones de empresas que así lo requieran.

La vicepresidenta de Competencia de la Comisión Europea, Margrethe Vestager, afirmó entonces que «las medidas de emergencia están presionando a muchas empresas a afrontar una reducción en el capital, con consecuencias negativas en su capacidad para financiar sus actividades». Es por ello que comunicaba su propuesta de ampliar aún más el marco temporal de ayudas estatales para que los Estados miembros puedan recapitalizar empresas cuando sea necesario y apropiado.

«Nos aseguraremos de que los contribuyentes reciban una remuneración suficiente por su inversión, y de que las empresas que reciban apoyo de capital estén sujetas a controles y disposiciones de gobernanza que limitan las posibles distorsiones de la competencia en el mercado único», subrayó.

«Dado que tales intervenciones públicas pueden tener un impacto significativo en la competencia en el mercado único, deberían seguir siendo medidas de último recurso», constataba.

La ampliación propuesta del alcance del marco temporal para ayudas en forma de recapitalizaciones complementaba la posibilidad de que los Estados miembros compren acciones de empresas a precios de mercado.

\section{Propuesta de Plan de Recuperación Económica de 750.000 millones de euros}

Los devastadores efectos económicos de la crisis sanitaria han puesto sobre la mesa el difícil debate sobre la asistencia a los Estados más afectados en el camino hacia la recuperación, un plan de recuperación que, en diferentes medios periodísticos, ha sido bautizado como el «Plan Marshall europeo».

La presidenta de la Comisión Europea, Ursula von der Leyen, presentó el 27 de Mayo ante el Parlamento Europeo un plan de estímulo sin precedentes que aspira a movilizar 750.000 millones de euros, de los cuales 500.000 millones serían transferencias a fondo perdido (grants), y los 250.000 restantes serían ofrecidos como préstamos en condiciones favorables. «Nuestra voluntad de actuar debe estar a la altura de los desafíos que todos encaramos,» afirmó Von der Leyen ante los eurodiputados.

La propuesta mereció el calificativo de «histórica» por el hecho de que, por primera vez en la historia de la UE, las ayudas contra una crisis consis- 
tirían mayoritariamente en subsidios y no serán, exclusivamente, préstamos reembolsables.

El hecho de que, en efecto, la mayor parte del desembolso pudiera consistir en ayudas a fondo perdido favorecería a países como España e Italia, particularmente afectados por la pandemia y permitiéndoles, asimismo, no incrementar su ya abultada Deuda pública. Los países tendrían que presentar, en todo caso, sus respectivos planes nacionales de inversión y de reformas alineados con las recomendaciones de Bruselas para acceder a los fondos y, también, con sus grandes prioridades, las transformaciones digital y ecológica.

Von der Leyen se reivindicaba así ante un Parlamento Europeo que la había acusado de falta de ambición. «Las medidas más audaces siempre son las mejores para Europa», señaló la alemana en la presentación de su plan de recuperación económica, bautizado simbólicamente como «Next Generation EU», «La UE de la próxima generación».

«Lo que empezó como un virus tan diminuto que no se ve», señaló la presidenta de la Comisión, «se ha convertido en una crisis tan grande que no se puede ignorar. Nuestro modelo, construido durante 70 años, se enfrenta a un desafío como nunca antes en la historia de nuestra Unión».

Según las estimaciones facilitadas en diferentes medios, España podría convertirse en el segundo mayor receptor del plan de recuperación económica, ya que podría llegar a recibir unos 140.000 millones de euros (de los 750.000 millones de dotación global del fondo), de los que hasta 77.000 millones serían transferencias y 63.000 millones, préstamos.

El Fondo de recuperación estaría integrado en la propuesta del ejecutivo comunitario del próximo Marco Financiero Plurianual, MFP, que marcará el presupuesto de la UE para el período 2021-2027, y que según esta propuesta podría movilizar hasta 1,85 billones durante los próximos siete años, focalizados en las partidas tradicionales de gasto como los Fondos de Cohesión o la Política Agrícola Común, aunque dando también más relevancia a temas como la digitalización, la descarbonización, la transición ecológica y la seguridad.

La Comisión Europea proponía, de esta forma, elevar temporalmente el techo de los recursos propios de la Unión en el presupuesto hasta el 2\% de la Renta Nacional Bruta y utilizar el margen adicional disponible entre el gasto real, que rara vez llega al 1\% de la RNB, y el nuevo techo (margen estimado en más de 100.000 millones de euros), para la emisión de Deuda conjunta con el objetivo de captar los 750.000 millones previstos en el plan de recuperación de los próximos años.

Por tanto, para disponer de los 750.000 millones, Bruselas proponía emitir Deuda con el aval del presupuesto de la UE, basándose también en la recaudación de nuevos impuestos, como las nuevas tasas ecológicas (sobre 
el $\mathrm{CO}_{2}$ o los plásticos), un impuesto digital o un impuesto a las grandes corporaciones.

Los distintos instrumentos «EU Next Generation» se desplegarían en tres pilares.

- Ayudar a los Estados miembros a recuperarse,

- Relanzar la Economía y apoyar la inversión privada,

- Aprender de la experiencia de la crisis.

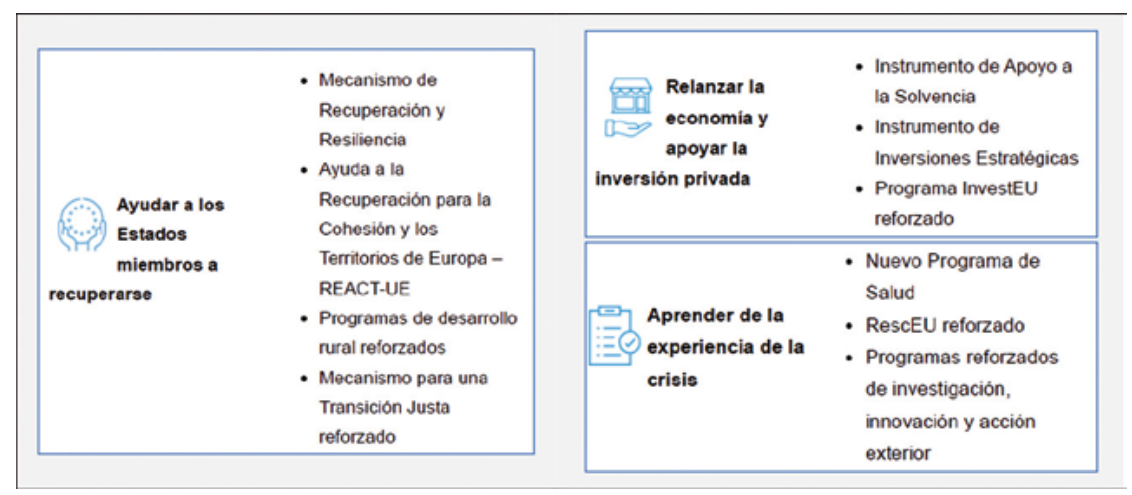

Instrumentos «Eu Next Generation»

Fuente: Comisión Europea

En el primer pilar destaca el llamado «Mecanismo de Recuperación y Resiliencia», que se destinaría a subvenciones y préstamos basados en la aplicación de los planes nacionales correspondientes definidos de acuerdo con los objetivos del Semestre Europeo y alineados, en particular, con las transiciones ecológica y digital. Y contaría con un presupuesto de 560.000 millones de euros (310.000 millones en ayudas y 250.000 en préstamos).

A ese instrumento se añadirían subvenciones flexibles de la política de cohesión para municipios, hospitales y empresas a través de las autoridades de gestión de los Estados miembros en el marco del instrumento denominado «React-EU» dotado con 55.000 millones de euros.

El segundo pilar se centraría en el reinicio de la actividad económica a través del estímulo de la inversión privada. Contempla la creación de dos fondos: un «Instrumento de Apoyo a la Solvencia» para respaldar a empresas en apuros por la pandemia al que se inyectarían 31.000 millones de euros y un «Fondo de Inversión Estratégica», con 15.000 millones. Además, la Comisión actualizaría el programa «InvestEU» para más que duplicar su capacidad. 
En el tercer pilar destaca un nuevo programa de salud llamado «EU4Health», destinado a reforzar la seguridad sanitaria y a mejorar la preparación de la UE de cara a futuras crisis en ese ámbito con un presupuesto de 9.400 millones de euros.

El paquete anunciado representaría el mayor estímulo fiscal de la UE en su historia para poder superar la recesión más profunda desde que el bloque se unió hace casi siete décadas. Von der Leyen dijo que los fondos beneficiarán especialmente a las regiones y sectores más afectados, aunque ciertamente todos los Estados miembros podrían acceder a ellos. La Comisión proponía una clave de asignación basada en una cantidad máxima de fondos a los que cada país podría acceder, siempre que sus planes nacionales de recuperación se ajusten a los criterios marcados por el ejecutivo comunitario.

La propuesta fue recibida con satisfacción por los presidentes de los gobiernos español, Pedro Sánchez, e italiano, Giuseppe Conte, dos de los líderes europeos que reclamaban una contundente respuesta europea desde el principio de la pandemia. El plan también contaba con el visto bueno de la canciller alemana, Angela Merkel, y del presidente francés, Emmanuel Macron ya que ambos habían declarado previamente su disposición a apoyar un plan de subsidios de hasta medio billón de euros.

Y el proyecto de Von der Leyen también recibió el parabién del Parlamento Europeo, con un respaldo mayoritario. De hecho, la Asamblea europea había exigido, por abrumadora mayoría, una movilización de hasta dos billones de euros contra la crisis. El presidente de la Cámara, el socialista David Sassoli, afirmó, en todo caso, que los 750.000 millones de euros de Von der Leyen respondían de manera satisfactoria esta petición «porque permitirá movilizar incluso una cifra superior a los dos billones gracias al atractivo que Europa tendría para los inversores».

Sin embargo, y a pesar de la extraordinaria ambición demostrada por la Comisión, «la negociación será muy complicada», tal como anticipó inmediatamente el presidente del Eurogrupo Mario Centeno, ya que comenzaba la difícil confrontación con el grupo de países contrarios a las transferencias a fondo perdido, Holanda, Dinamarca, Suecia y Austria.

Los expertos vaticinaban, sin embargo, que aun siendo difícil el empeño no era imposible: Holanda ha recibido graves acusaciones de beneficiarse de ingresos públicos de otros países europeos por su condición de semiparaíso fiscal, en Austria podría confiarse en los verdes que lideran el europeísmo en el gobierno, y Suecia debería contrarrestar el incumplimiento que significa rechazar la obligación jurídica de incorporarse al euro; por último, parece evidente que Dinamarca carecería del peso suficiente para paralizar en solitario al continente. 
Además, fuentes de la Comisión apuntaron el argumento de que estos países son los mayores beneficiarios del Mercado Interior ya que, según estas fuentes, este espacio económico europeo les reporta una riqueza de unos 1.500 euros per cápita, el doble que a Italia (763 euros) y casi el triple que a España (589 euros). Y el plan presupuestario de la Unión les ofrece, además, mantener los cheques de rebaja en su contribución anual.

Y, en todo caso, Bruselas vincularía los desembolsos del Plan de Recuperación a una condicionalidad ligada a los planes nacionales de reforma, para garantizar que el gasto redunde en beneficio de la competitividad y la modernización de los países auxiliados.

En el Consejo Europeo celebrado el 19 de junio los Estados miembros escenificaron las diferencias que les separaban y el único compromiso al que llegaron los Jefes de Estado y de Gobierno de los Veintisiete fue el relativo a la necesidad de acelerar los trabajos para intentar llegar a un acuerdo en la siguiente cumbre que se celebraría previsiblemente en la segunda quincena del mes de julio.

La reunión sí sirvió para constatar la aceptación de la propuesta de Comisión como la base de la negociación y, también, la aceptación de la fórmula de financiación del plan, consistente en la emisión de Deuda con el aval de los Estados miembros a través del presupuesto de la UE.

\section{BCE: nuevos programas de compras masivas de Deuda de marzo y junio}

En un consejo de gobierno de urgencia celebrado en la noche del 18 de marzo, el Banco Central Europeo aprobó un plan de compra masiva de activos públicos y privados, hasta finales de año, de 750.000 millones de euros, como programa de emergencia para combatir la pandemia del coronavirus.

Aunque seguirá el diseño de anteriores programas y, por tanto, se ejecutará de forma proporcional al tamaño de cada Economía, el BCE introducía una novedad importante al asegurar que «las compras bajo el nuevo programa se realizarán de manera flexible», lo que significa que podría comprar más Deuda de países como Italia o España si lo considerase necesario. «Esto permite fluctuaciones en la distribución de los flujos de compra a lo largo del tiempo, entre las clases de activos y entre las jurisdicciones», señalaba el comunicado.

El BCE justificó su decisión en el hecho de que el coronavirus es un shock generalizado y que no corresponde a irresponsabilidades de los países más golpeados por la pandemia. Y por otra parte, el Banco se basaba en el claro riesgo de deflación que sufre la Eurozona como consecuencia de la drástica caída de la demanda. 
«Los tiempos extraordinarios requieren acciones extraordinarias. No hay límites en nuestro compromiso con el euro», tuiteó Christine Lagarde, presidenta del BCE, nada más hacerse público el programa de compras.

Por su parte, el 8 de Mayo el Tribunal de Justicia de la UE emitió un insólito comunicado de prensa en el que se pronunciaba con dureza respecto a la sentencia del Tribunal constitucional alemán que, apenas tres días antes, el 5 de Mayo, había cuestionado un programa de compra de bonos puesto en marcha por el BCE en 2015, en abierta contradicción con una sentencia anterior del propio Tribunal europeo.

El Constitucional alemán no solo cuestionaba la legalidad del programa de compra de Deuda del BCE sino que, además, se negaba, por primera vez en la historia judicial de Alemania, a acatar la sentencia de Luxemburgo que anteriormente había validado las compras del BCE ante una consulta prejudicial del mismo Tribunal constitucional alemán.

En su pronunciamiento, la Corte de Luxemburgo criticaba con dureza la sentencia del Tribunal de Karlsruhe por haberse permitido juzgar la actuación de una institución comunitaria como es el BCE y haber puesto en jaque toda la arquitectura jurídica de la UE.

«El Tribunal de Justicia de la UE es el único competente para declarar que un acto de una institución de la Unión es contrario al Derecho de la Unión», señalaba el histórico comunicado de Luxemburgo, advirtiendo además de que «las divergencias entre órganos jurisdiccionales de los Estados Miembros sobre la validez de dichos actos pueden llegar a comprometer la unidad del ordenamiento jurídico de la UE y perjudicar la seguridad jurídica».

$\mathrm{El}$ «desaire» del Constitucional alemán a Luxemburgo fue interpretado por diferentes medios como un peligroso precedente para la Unión Europea, y es por ello que el contundente comunicado del Tribunal de Luxemburgo intentó, de manera inmediata, neutralizar esta potencial «onda expansiva» de la sentencia alemana, cuyas repercusiones políticas podrían llegar a ser mucho más relevantes que las económicas.

Y el 4 de junio, el BCE decidió ampliar el programa de compras de activos vinculado a la pandemia en 600.000 millones de euros y extenderlo al menos hasta junio de 2021 ante la revisión a la baja de la inflación y el descalabro económico previsto para la zona euro.

Sumando las decisiones de marzo y junio, el programa de compra de Deuda suma 1,35 billones de euros que se irá ejecutando hasta «al menos junio de 2021» o, en cualquier caso, hasta que el consejo de gobierno del BCE considere que la pandemia ha finalizado. A partir de entonces, y hasta al menos finales de 2022, los vencimientos de la Deuda se seguirán reinvirtiendo. 
En la comparecencia posterior al consejo de gobierno del BCE, Lagarde justificó las medidas adoptadas en la necesidad de «apoyar la Economía durante la reapertura gradual» y «proteger la estabilidad de precios a medio y largo plazo» cuando la zona euro se ve amenazada por la deflación.

\section{Estados miembros de la UE: Decisiones de cierres de frontera y restricciones a los movimientos de ciudadanos}

Por primera vez en la historia de la Unión Europea, los líderes de los Estados miembros de la UE pactaron el 16 de marzo el cierre generalizado de las fronteras exteriores y la prohibición de entrada a los ciudadanos de terceros países salvo en circunstancias excepcionales. Únicamente podrían realizarse los viajes considerados «estrictamente necesarios», como por ejemplo los de repatriación de ciudadanos europeos bloqueados en países terceros.

«Hemos acordado adoptar una decisión coordinada para restringir los viajes no esenciales a la UE», anunció el presidente del Consejo Europeo, Charles Michel, tras una cumbre por videoconferencia, en la que los líderes europeos aprobaron, una medida excepcional cuyo objetivo no era otro que contener la expansión del coronavirus en la Unión.

Posteriormente, y dado que la gestión de las fronteras es una competencia exclusiva de los Estados, la Comisión solicitó de los Estados miembros la prórroga de este cierre temporal de fronteras exteriores y, en particular, la del espacio Schengen. El 12 de junio proponía una ampliación del cierre de fronteras, que expiraba entonces el 15 de junio, hasta, al menos, el 1 de julio.

En todo caso, la Comisión recomendaba el 12 de junio que antes de iniciar la apertura de las fronteras exteriores, los Estados miembros deberían abrir plenamente las interiores. Es por ello que aprobó una recomendación dirigida a todos los países miembros de la zona Schengen para que levantaran los controles fronterizos internos antes del 15 de junio para iniciar el proceso de apertura de fronteras exteriores al resto del mundo a partir del 1 de julio, de una manera «progresiva y diferenciada» en función de la situación sanitaria de cada país extra comunitario.

En su solicitud, Bruselas recomendaba a los Estados que finalizaran el proceso de levantamiento de controles y restricciones al libre movimiento de personas dentro de la UE para el 15 de junio de 2020, recomendación que fue aceptada por diferentes países como Italia, Alemania, Bélgica y Francia, mientras España decidía hacerla efectiva el 21 de junio. 
En efecto, ya en marzo una buena parte de los 27 países de la UE habían decidido restablecer los controles fronterizos internos e, incluso, impedir la entrada de ciudadanos europeos o someterlos a una cuarentena obligatoria aunque no presentaran síntomas ni procedieran de zonas con numerosos contagios.

La alarma también se visibilizó cuando algunos Estados decidieron restringir o prohibir exportaciones de fármacos $\mathrm{y}$ otros productos $\mathrm{y}$ aparatos médicos y sanitarios, contribuyendo de este modo a acrecentar el riesgo de desabastecimiento en los Estados miembros más afectados por la pandemia. La Comisión decidía por tal motivo aprobar un reglamento que prohibía la exportación fuera de la UE de material de protección como mascarillas o guantes, para garantizar el abastecimiento.

A partir del 1 de julio, por tanto, la UE iniciará la apertura escalonada de las fronteras con terceros países con una serie de condicionantes, como que la situación epidemiológica de estos países sea «análoga o mejor que la de la UE», que los viajeros asuman «condiciones sanitarias en origen, trayecto y destino», y que estos países actúen con reciprocidad, es decir, que estén dispuestos, también, a permitir la entrada de viajeros procedentes de la UE.

Y para hacerla efectiva, la Comisión Europea debería elaborar un listado con las restricciones a terceros países, aplicable al conjunto de países de la UE.

\section{Brexit: el nacimiento de la Unión Europea de los Veintisiete el 31 de enero}

En la medianoche del 31 de enero el Reino Unido abandonó la UE tras tres años de indecisiones políticas y en un clima de gran división en la ciudadanía británica. Aunque el primer ministro Boris Johnson prefirió la contención respecto al momento histórico que vivía el país, sí habló de «una nueva era» y de «momento de renovación nacional».

A pesar de la mayoría absoluta del partido conservador, conseguida en las elecciones del 12 de Diciembre, lo que podría significar que las controversias internas en relación a la «cuestión europea» habrían terminado, muchos analistas aventuraban el inicio a otro debate entre «tories», entre los partidarios del libre comercio sin ninguna atadura respecto a las reglas de la UE y los temerosos de las nefastas consecuencias que este Brexit «duro» provocaría en la actividad económica británica.

La confrontación adquiere además una nueva dimensión desde el momento en que la ministra principal de Escocia, Nicola Sturgeon, aseguraba en diferentes medios que «la mejor opción para Escocia es ser una nación independiente, dentro de la UE». De hecho, dos de las cuatro naciones del 
Reino Unido, Escocia e Irlanda del Norte, rechazaron en el referéndum de 2016 el «divorcio» de Bruselas y sus dirigentes no ocultan la posible eventualidad de «divorciarse» de Londres.

Johnson, por su parte, había prometido en la campaña electoral que un Reino Unido «liberado de las cadenas» de la UE crearía cientos de miles de empleos nuevos, basando esta promesa en el cierre de nuevos Tratados comerciales con países como Estados Unidos, Australia, Nueva Zelanda o Japón, que pudieran compensar la pérdida de las ventajas de las que ha disfrutado el país con el Mercado Único europeo durante 47 años.

En la Unión Europea se escucharon llamamientos a la unidad de los Veintisiete socios. Los máximos representantes del Consejo de la UE, Charles Michel, de la Comisión Europea, Ursula Von der Leyen, y del Parlamento Europeo, David Sassoli, recordaron que ningún país europeo es tan grande y tan rico como para afrontar de manera individual los embates de la globalización.

La canciller alemana, Angela Merkel, aventuró la posibilidad de que el Reino Unido siga siendo «un estrecho aliado y amigo», lo que contrastaba con anteriores mensajes en los que había calificado a los británicos como de un temible competidor. Por su parte, el presidente francés, Emmanuel Macron, señaló que el Brexit debe interpretarse como «una histórica señal de alarma», en una alusión implícita al crecimiento de los partidos euroescépticos en Europa.

En todo caso, se iniciaba también entonces, el 1 de Febrero, una nueva etapa en las negociaciones, encaminadas a acordar antes del 31 de Diciembre los términos de la nueva relación entre el Reino Unido y la UE de los Veintisiete.

De hecho, en realidad nada cambió el 1 de Febrero puesto que las normas comunitarias siguen aplicándose en el Reino Unido de manera transitoria hasta fin de año. Pero conocida la intención de no pactar nuevas prórrogas, tal como se aprobó en la legislación británica de salida de la UE en Diciembre, las breves negociaciones de tan sólo once meses podrían descarrillar y, por tanto, el Brexit duro aún podría ser una realidad.

Los negociadores de la UE, liderados por el francés Michel Barnier, recibían el mandato de pactar dos grandes bloques; por una parte, el económico, que incluye diferentes acuerdos tan importantes como los que deberían garantizar el libre comercio o la colaboración en materia de pesca o de energía, y un segundo bloque sobre seguridad, que incluiría ámbitos de cooperación policial y de acción exterior, entre otros.

La consecución de un acuerdo comercial con aranceles cero y sin cuotas resulta ser de interés para ambas partes; para la UE porque sin duda desearía mantener su superávit comercial con los británicos, y para el Reino 
Unido por la intensidad de sus relaciones comerciales con el bloque (el comercio del país con la UE-27 representa el $45 \%$ de sus exportaciones y el $53 \%$ de sus importaciones).

Los representantes europeos ya planteaban en el comienzo de esta nueva etapa que su intención era llegar a unas relaciones comerciales estrechas, pero condicionadas a la igualdad de condiciones en materia fiscal, laboral, medioambiental y de ayudas de Estado. Afirmaban su objetivo de evitar que el Reino Unido se convierta en un competidor «desleal» situado a apenas 34 kilómetros de la costa europea. La prioridad en la negociación de la UE deberá ser preservar con los británicos el Mercado Único y, también, su «ecosistema reglamentario».

Muchos analistas diferenciaban, de forma gráfica, el «Brexit político» que tuvo lugar el 31 de Enero, y el «Brexit económico» que, previsiblemente se iniciará el 1 de Enero de 2021.

En todo caso, los avances para alcanzar un acuerdo económico han sido mínimos en los primeros meses del año debido, en gran parte, a la paralización política y económica derivada de la pandemia del coronavirus.

En una cumbre, celebrada por videoconferencia el 15 de junio, los máximos líderes de ambas partes, Von der Leyen, Michel y Sassoli por parte de la UE y Boris Johnson por parte británica, se comprometieron a dar un nuevo impulso a este diálogo e intensificarlo a partir de julio, aunque ciertamente el encuentro no anticipó grandes avances, en parte también por la decisión británica, dada por definitiva, de no pedir una prórroga del período transitorio.

Johnson explicó, al término de la videoconferencia, los objetivos que persigue en este nuevo impulso negociador y sus principales líneas rojas: «No podemos seguir subordinados en este país a las decisiones del Tribunal de Justicia europeo; no podemos seguir en un sistema en el que debemos continuar obedeciendo las leyes de la UE aunque ya estemos fuera», señaló.

\section{Nuevo expediente a Polonia por no respetar la independencia judicial}

La Comisión Europea anunció el 29 de Abril la apertura de un nuevo procedimiento de infracción contra el gobierno ultraconservador polaco liderado por el partido Ley y Justicia.

Se trata del cuarto procedimiento contra este país en los últimos tres años y en esta ocasión el expediente se centra en las reformas judiciales emprendidas por Varsovia y que entraron en vigor a mediados de Febrero. Entre otras medidas, estas controvertidas normas otorgan al Tribunal Supremo polaco la competencia exclusiva para pronunciarse sobre la indepen- 
dencia judicial, exigen a los jueces que divulguen información sobre sus actividades no profesionales, y amplían la noción de delito disciplinario.

«Existen riesgos claros de que el régimen disciplinario pueda ser utilizado para ejercer un control político sobre las decisiones judiciales», advertía la vicepresidenta checa de la Comisión, Vera Jourová.

Según Bruselas, esta normativa es incompatible con el Derecho europeo puesto que impide a los tribunales polacos aplicar directamente ciertas disposiciones de la legislación comunitaria que protegen la independencia judicial, como por ejemplo plantear ciertas cuestiones prejudiciales al Tribunal de Justicia de la Unión. «Nuestro análisis ha sido muy cauteloso», añadió Jourová, quien recordó que el ejecutivo comunitario está listo para «un diálogo» con el gobierno polaco.

La apertura del expediente supone, en efecto, el primer paso por parte de la Comisión en un proceso que podría llegar ante el Tribunal de Justicia de la UE si el gobierno polaco no reculara, tal como sucedió en 2019.

Entonces, Bruselas denunció a Polonia ante el Tribunal de Luxemburgo por otro asunto relacionado con esta cuestión, el régimen disciplinario aplicable a los jueces del Tribunal Supremo y otras instancias, y el 8 de Abril la Corte europea sentenció que Polonia debía suspender «de manera inmediata» dicho régimen disciplinario.

Durante su intervención, la comisaria checa también anunció que las autoridades comunitarias no habían hallado argumentos jurídicos lo suficientemente sólidos como para abrir expediente a Hungría por el modo en que estaba gestionando su estado de emergencia por la pandemia. Este país había recibido críticas de sus socios comunitarios por la amplitud de las competencias asumidas por el ejecutivo húngaro con la excusa de combatir la expansión del coronavirus.

Jourová insistió en que «el virus no puede matar la democracia», e insinuó que Hungría podría también ser denunciada si la deriva autoritaria de Viktor Orbán se recrudece. «Los gobiernos tienen buenas razones para pedir poderes especiales, pero esos regímenes excepcionales no implican que los parlamentos deban paralizarse, los periodistas no puedan expresarse, $o$ que la democracia sea suspendida», advirtió.

\section{Cuestiones generales de la actualidad económica}

\section{Debate sobre la reforma de la Gobernanza Económica Europea}

La Comisión Europea presentó el 5 de Febrero una evaluación sobre la eficacia del marco de supervisión económica, macroeconómica y presupuestaria de la UE, para iniciar un debate público sobre su futuro. 
Según el ejecutivo comunitario este marco de supervisión económica ha contribuido a lograr una coordinación más estrecha de las políticas económicas, valorando los desequilibrios macroeconómicos y apoyando la reducción de los déficits públicos y los niveles de Deuda, y, por tanto, es un elemento clave para la consecución de la estrategia de la Unión en favor del crecimiento sostenible y del empleo.

Sin embargo, Bruselas también reconoció la existencia de ciertos aspectos de vulnerabilidad del sistema, incluida la extrema complejidad del marco presupuestario común.

De esta forma, y coincidiendo con el inicio de un nuevo ciclo político en las instituciones comunitarias, la Comisión consideraba llegado el momento de evaluar la eficacia de este marco de supervisión económica, y en especial de los llamados Six-Pack y Two-Pack de la conocida como «Gobernanza Económica de la UE».

El examen presentado tenía como objetivo evaluar la eficacia de los distintos instrumentos de supervisión a la hora de alcanzar tres objetivos clave:

- garantizar la sostenibilidad de las finanzas públicas y el crecimiento económico, evitando los desequilibrios macroeconómicos,

- permitir una coordinación más estrecha de las políticas económicas,

- y fomentar la convergencia en los resultados económicos de los Estados miembros.

Las conclusiones de esta evaluación mostraban resultados positivos, como el hecho de que el marco de supervisión ha ayudado a corregir los desequilibrios macroeconómicos existentes y a reducir la Deuda pública, contribuyendo a crear las condiciones necesarias para el crecimiento sostenible, el refuerzo de la resiliencia y la reducción de las vulnerabilidades ante las perturbaciones económicas. También ha promovido una convergencia sostenida de los resultados económicos de los Estados miembros y una coordinación más estrecha de las políticas presupuestarias dentro de la zona del euro.

Sin embargo, la Comisión reconocía que la Deuda pública seguía siendo elevada en algunos Estados miembros y que la orientación presupuestaria a nivel nacional es, a menudo, procíclica.

Por otra parte, el examen también llegaba a la conclusión de que, como consecuencia de la necesidad de atender a una amplia variedad de circunstancias cambiantes, el marco presupuestario se ha vuelto excesivamente complejo y, por tanto, menos transparente y previsible.

En opinión de la Comisión, para que la supervisión económica sea eficaz en la UE resulta crucial un alto grado de consenso y de confianza entre todas las partes interesadas. Y por esta razón, Bruselas invitaba a las demás 
instituciones europeas, a las autoridades nacionales, a los interlocutores sociales y al mundo académico en general, a participar en el debate a fin de dar a conocer sus opiniones sobre la forma en que ha funcionado hasta ahora el marco de «Gobernanza Económica» y sobre las posibles maneras de mejorar su eficacia.

Este diálogo debería tener lugar a través de diversos medios, tales como reuniones, talleres y una plataforma de consulta online, de tal manera que la Comisión podría tener en cuenta las opiniones de las partes interesadas y el resultado de estas consultas cuando complete sus reflexiones internas sobre posibles medidas futuras. Este proceso debería concluir a finales de 2020.

\section{Key findings of review} The review finds that the six-pack and two-pack legislation has helped Mernber States to achieve their economic and fiscal
policy objectives. At the same time, it identifies possible areas for improvernent.

\section{Strengths of the framework: \\ $\checkmark$ Correction of excessive deficits \\ $\checkmark$ Correction of macroeconomic imbalances \\ $\checkmark$ Reduction of vulnerabilities to shocks \\ $\checkmark$ Economic convergence in the EU \\ $\checkmark$ Coordination of economic policies}

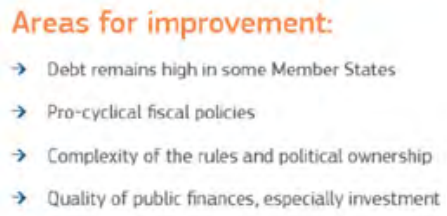

$\rightarrow$ Quality of public finances, especially investment

Examen de la Gobernanza Económica de la UE

Fuente: Comisión Europea https://ec.europa.eu/commission/presscorner/detail/es/ip_20_170

\section{El «Semestre Europeo 2020»}

El Semestre Europeo 2020 comenzó en Diciembre de 2019 con la publicación de los dos análisis preceptivos de coordinación de las políticas económicas, presupuestarias y sociales de los Estados miembros: el documento titulado «Estrategia Anual de Crecimiento Sostenible», EACS, que establece la estrategia de política económica y de empleo de la UE, y el llamado «Informe del Mecanismo de Alerta», IMA, que en esta ocasión recomendaba que trece Estados miembros debían someterse a un Examen Exhaustivo para determinar y evaluar la gravedad de sus desequilibrios macroeconómicos.

De esta forma, en Febrero, la Comisión presentó estos informes y llegó a las conclusiones siguientes en relación a la existencia de eventuales desequilibrios macroeconómicos: 
- Grecia, Italia y Chipre seguían experimentando desequilibrios excesivos;

- Alemania, Irlanda, España, Países Bajos, Francia, Croacia, Portugal, Rumanía y Suecia seguían experimentando desequilibrios;

- Bulgaria ya no experimentaba desequilibrios.

Según estos «Informes por país», la aplicación de las recomendaciones adoptadas en 2019 podía considerarse como sólida en los ámbitos de los servicios financieros y las políticas activas del mercado de trabajo, mientras que la ejecución de las reformas seguía siendo baja en ámbitos como la competencia en los servicios y la sostenibilidad a largo plazo de las finanzas públicas.

Por lo que se refiere al Informe sobre España, la Comisión incidía, de nuevo, en el elevado nivel de Deuda pública, que equivalía entonces al 96\% del PIB y que reflejaba un alto grado de vulnerabilidad. Pero el ejecutivo comunitario también criticaba la total ausencia de avances en materia de reformas tributaria y de las pensiones.

En cuanto a la recaudación tributaria, el informe ponía de manifiesto que la presión fiscal en España asciende al 34,7\% del PIB con datos de 2018, porcentaje inferior a los promedios de la UE y de la zona del euro, que son del $39,2 \%$ y el 40,6\%, respectivamente. Concretamente, la Comisión veía margen para una mayor recaudación por el IVA, pasando la imposición de los artículos gravados actualmente con tipos reducidos $(10 \%)$ y superreducidos (4\%) al tipo general (21\%). Asimismo, apuntaba que también había recorrido para aumentar los impuestos verdes, cuya recaudación era del 1,8\% del PIB en 2018, comparado con el promedio de la UE de cerca del $2,4 \%$.

Y respecto a las pensiones, Bruselas criticaba que el gobierno español hubiera renunciado al factor de revalorización y suspendido el de sostenibilidad, habiendo actualizado las prestaciones con el IPC, lo que significaba el aceleramiento del crecimiento del gasto en pensiones.

Como continuación de la secuencia de actuaciones previstas en el Semestre Europeo, en Abril los Estados miembros presentaron sus respectivos Programas de Estabilidad o Convergencia, y Planes Nacionales de Reforma.

En el caso español, el Programa de Estabilidad recogía la actualización del escenario macroeconómico para 2020 y 2021, mostrando los efectos económicos de la irrupción del coronavirus e incluyendo las medidas establecidas en el Estado de alarma para mitigar el impacto de la pandemia en familias, trabajadores, autónomos y empresas

El nuevo cuadro macroeconómico estimaba una caída del PIB del $9,2 \%$ en el conjunto del año y una importante recuperación en 2021, con 
una tasa de crecimiento prevista del 6,8\%. Asimismo, preveía que la tasa de paro se sitúe en el 19\% en 2020, para reducirse en 2021 hasta el entorno del $17 \%$.

Respecto a las cuentas públicas, el gobierno preveía que la incidencia de las iniciativas de apoyo a familias, trabajadores y empresas para mitigar los efectos sociales y económicos de la pandemia, supondrán un incremento del déficit público en 2020 que se situará, previsiblemente, en el 10,3\% del PIB y que la Deuda pública alcanzará el $115,5 \%$.

Por lo que se refiere al Programa Nacional de Reformas presentado por España, el gobierno destacaba la agenda de medidas puestas en marca para proteger a los ciudadanos y para preservar la actividad económica y el empleo en el marco de la excepcionalidad de la pandemia. Señalaba haber abordado también importantes reformas estructurales, entre las que destacaba el establecimiento de un régimen ágil de Expedientes de Regulación Temporal de Empleo, la puesta en marcha de un sistema de gestión de información en el ámbito sanitario, el fomento del teletrabajo, el impulso de la digitalización en el ámbito educativo, en las empresas, en la justicia y en el Servicio Público de Empleo, el desarrollo de un sistema de gestión de las prestaciones de la Seguridad Social a través de las mutuas profesionales y el desarrollo de aplicaciones basadas en la inteligencia artificial para la gestión de la movilidad.

El siguiente hito del Semestre 2020 tuvo lugar el 20 de Mayo, cuando la Comisión presentó sus «Recomendaciones Específicas por país», REP de 2020, en las que exponía las orientaciones en materia de política económica que dirige a cada Estado miembro para los próximos meses.

Aunque tradicionalmente estas recomendaciones se basan en los documentos previos del Semestre (prioridades generales establecidas en la EACS de Diciembre, Informes por país publicados en Febrero y evaluación de los Programas Nacionales presentados en Abril), en esta ocasión se vieron lógicamente condicionadas por la necesidad de articular una respuesta urgente a los efectos causados por la crisis sanitaria.

En el caso español, Bruselas detallaba una lista de peticiones para amortiguar el desajuste en el mercado laboral, ya que la tasa de paro podría llegar hasta el $19 \%$ este año. Entre otras recomendaciones, planteaba medidas encaminadas a preservar los puestos de trabajo e incentivos «eficaces» a la contratación.

En el apartado de la protección social, la institución comunitaria recomendaba la mejora de la cobertura y la adecuación de los regímenes de renta mínima y de apoyo a las familias, dados los preocupantes niveles de pobreza, que previsiblemente aumentarán a causa de la crisis sanitaria. 
3. Competencia: protección de las empresas europeas afectadas por la crisis sanitaria y veto a las inversiones chinas

La Comisión Europea anunció en junio un plan para proteger el tejido empresarial europeo, muy debilitado por la crisis del coronavirus y por ello, posible objetivo de empresas extracomunitarias que, en su caso, se hubieran podido ver reforzadas por las ayudas y el capital público recibidos en sus países.

En el denominado oficialmente «Libro Blanco sobre el impacto de los subsidios públicos extranjeros en el Mercado Único», planteaba una ambiciosa batería de medidas con las que frenar la rivalidad desleal foránea, vetando incluso aquellas operaciones que pudieran distorsionar la competencia.

«Necesitamos las herramientas adecuadas para garantizar que las subvenciones extranjeras no falseen nuestro mercado, al igual que hacemos con las subvenciones nacionales», aseguró la vicepresidenta del ejecutivo comunitario y responsable de Competencia, Margrethe Vestager, durante la presentación de la propuesta.

La salvaguarda de la Comisión pivota sobre tres grandes ejes.

En primer lugar, pretende crear un escudo contra posibles operaciones de compra de empresas extranjeras (por ejemplo, chinas) que, en su caso, pudieran ser consideradas como inversoras «no deseadas» en sectores estratégicos (por ejemplo, en aerolíneas, empresas energéticas, empresas de telecomunicaciones o entidades bancarias), aprovechando el hundimiento del valor de estas empresas europeas.

Además, Bruselas extremaría la vigilancia sobre aquellas compañías foráneas que ya operan en la UE y que pudieran estar «dopadas» con capital público extranjero, lo que les otorgaría una ventaja competitiva.

Y el tercer eje de protección serían las licitaciones públicas. La Comisión podría vetar la participación de empresas de terceros países reforzadas con capital público en estos procesos si determinase que tienen «un efecto nocivo». Es una medida de gran calado, puesto que cada año se celebran en la UE concursos estatales por valor de 2 billones de euros (más del 14\% del PIB comunitario).

El principal argumento que esgrime Bruselas es que «las subvenciones extranjeras pueden permitir a los licitadores obtener una ventaja injusta. En este contexto, el ejecutivo comunitario plantea que los licitadores tengan la obligación de notificar a los órganos de contratación las contribuciones financieras recibidas de terceros países, analizando también las empresas subsidiadas en la UE. 


\section{Competencia: investigaciones contra Apple}

La Comisión Europea anunció en junio la apertura de dos investigaciones antitrust a la multinacional estadounidense Apple por posibles prácticas contrarias a la libre competencia relacionadas con su tienda de aplicaciones App Store y con su plataforma de pagos Apple Pay.

Respecto al primer contencioso, Bruselas analizará si la tecnológica americana impone restricciones ilegales a las empresas que distribuyen sus contenidos digitales a través de su tienda App Store para favorecer sus propios servicios digitales.

Las compañías que, en efecto, quieren ofrecer contenido digital a los usuarios de Apple tienen que subir sus apps a la tienda de Apple. Y según la denuncia formulada por la compañía de música Spotify en 2019 Apple le cobra una comisión del $30 \%$ en las suscripciones a su servicio de música a través de su tienda App Store.

De esta forma, si Spotify decidiera vender su servicio de suscripción musical en la App Store de Apple, ésta conseguiría un 30\% de cada pago mensual (comisión que se rebaja al 15\% transcurrido el primer año).

La plataforma sueca asegura que si pagara esta comisión tendría que subir sus precios por encima de los que ofrece Apple Music. De hecho, Spotify no permite esta fórmula de suscripción a sus clientes para «poder mantener el precio competitivo», según explicó la compañía en el comunicado en el que anunciaba la presentación de la queja formal ante la Comisión.

También la compañía japonesa Rakuten presentó una acusación contra Apple ante el ejecutivo comunitario en marzo. A través de su filial Kobo, denunció prácticas contrarias a la libre competencia en el ámbito de los libros electrónicos y los audiolibros, al competir con Apple Books.

Tras una investigación preliminar en relación con estas quejas, Bruselas mostró su preocupación acerca de que las restricciones que impone Apple pueden distorsionar la libre competencia. «Los competidores de Apple han decidido desactivar la posibilidad de suscripción en la aplicación o han aumentado los precios del servicio a los consumidores para transferirles la comisión que les cobra Apple. En ambos casos, no se les permitió informar a los usuarios sobre posibilidades alternativas de suscripción fuera de la app de Apple», señalaba en un comunicado.

Es por ello que es previsible que Bruselas también examine por qué Apple no permite a las compañías informar a los usuarios de aplicaciones en iPhone y de iPad de que existen alternativas para adquirir contenidos digitales, por ejemplo en sus webs, de manera más económica que a través de las compras dentro de las aplicaciones que impone Apple.

Bruselas considera que la imposición de un sistema propio de compras en las aplicaciones parece dar a Apple un «control total» sobre los 
clientes de sus competidores que deseen suscribirse a contenidos digitales a través de aplicaciones para iPhone/iPad, lo que incluso podría permitir a Apple obtener datos valiosos sobre las «actividades y ofertas» de estas compañías.

Respecto a la segunda investigación, Bruselas anunció que examinaría si los términos y condiciones que impone Apple a las empresas que integran Apple Pay en sus servicios de pago son contrarias a las normas europeas de la competencia y reducen la innovación en el mercado. También investigará restricciones derivadas del hecho de que Apple Pay sea el único sistema de pago con el que los propietarios del iPhone pueden acceder a la función rápida de pago «tocar y listo». 


\section{Derechos de autor}

Los derechos de autor (para la distribución, comunicación pública, reproducción e inclusión en bases de datos de indexación y repositorios institucionales) de esta publicación (Cuadernos Europeos de Deusto, CED) pertenecen a la editorial Universidad de Deusto. El acceso al contenido digital de cualquier número de Cuadernos Europeos de Deusto es gratuito inmediatamente después de su publicación. Los trabajos podrán leerse, descargarse, copiar y difundir en cualquier medio sin fines comerciales y según lo previsto por la ley; sin la previa autorización de la Editorial (Universidad de Deusto) o el autor. Así mismo, los trabajos editados en CED pueden ser publicados con posterioridad en otros medios o revistas, siempre que el autor indique con claridad y en la primera nota a pie de página que el trabajo se publicó por primera vez en CED, con indicación del número, año, páginas y DOI (si procede). Cualquier otro uso de su contenido en cualquier medio o formato, ahora conocido o desarrollado en el futuro, requiere el permiso previo por escrito del titular de los derechos de autor.

\section{Copyright}

Copyright (for distribution, public communication, reproduction and inclusion in indexation databases and institutional repositories) of this publication (Cuadernos Europeos de Deusto, CED) belongs to the publisher University of Deusto. Access to the digital content of any Issue of Cuadernos Europeos de Deusto is free upon its publication. The content can be read, downloaded, copied, and distributed freely in any medium only for non-commercial purposes and in accordance with any applicable copyright legislation, without prior permission from the copyright holder (University of Deusto) or the author. Thus, the content of CED can be subsequently published in other media or journals, as long as the author clearly indicates in the first footnote that the work was published in CED for the first time, indicating the Issue number, year, pages, and DOI (if applicable). Any other use of its content in any medium or format, now known or developed in the future, requires prior written permission of the copyright holder. 